\title{
Comparison of Various Cold Sterilization Techniques on Routinely used Carbide Burs and Diamond Points
}

\author{
${ }^{1}$ Suganthi Ranganathan, ${ }^{2}$ Supriya Manvi, ${ }^{3}$ Srivatsa Gopalakrishna, ${ }^{4}$ Chaitra Koppal Renukanath
}

\section{ABSTRACT}

Aim: The aim of this study is to compare the various cold sterilization techniques for sterilizing dental burs and diamond points by assessing the microbial growth in culture media on them before and after sterilization.

Materials and methods: The following four disinfectants were used: $2 \%$ glutaraldehyde, $5.2 \%$ sodium hypochlorite, hydrogen peroxide, and $70 \%$ ethanol. There were two main groups taken as group I-carbide burs and group II—diamond burs. A total of 48 samples were collected, 12 samples per disinfectant. Each sample has two burs collected from same patient. One acts as control group which means only microbial count was determined without disinfection. The other one would be determined as microbial count before and after disinfection. The microbial assessment was done using brain heart infusion $(\mathrm{BHI})$ broth and counted by plating in chocolate blood agar and MacConkey agar.

Results: The obtained results were statistically analyzed by one-way analysis of variance (ANOVA) test and post hoc test. The results revealed that there was statistically significant difference between sodium hypochlorite and surgical spirit, sodium hypochlorite and hydrogen peroxide. There was no statistically significant difference between sodium hypochlorite and glutaraldehyde.

Conclusion: The results of this study revealed that sodium hypochlorite and glutaraldehyde are most effective than hydrogen peroxide, and surgical spirit is the least effective disinfectant. However, there was clinical significance in level of disinfection of all four disinfectants.

Keywords: Glutaraldehyde, Hydrogen peroxide, Sodium hypochlorite, Surgical spirit.

How to cite this article: RanganathanS, ManviS, GopalakrishnaS, Renukanath CK. Comparison of Various Cold Sterilization Techniques on Routinely used Carbide Burs and Diamond Points. Int J Prosthodont Restor Dent 2017;7(3):97-102.

\section{Source of support: Nil}

Conflict of interest: None

\footnotetext{
${ }^{1}$ Postgraduate Student, ${ }^{2}$ Professor, ${ }^{3}$ Principal and Professor ${ }^{4}$ Reader

${ }^{1-3}$ Department of Prosthodontics and Implantology, KLE Society's Institute of Dental Sciences, Bengaluru, Karnataka India

${ }^{4}$ Department of Microbiology, KLE Society's Institute of Dental Sciences, Bengaluru, Karnataka, India
}

Corresponding Author: Suganthi Ranganathan, Postgraduate Student, Department of Prosthodontics and Implantology, KLE Society's Institute of Dental Sciences, Bengaluru, Karnataka, India Phone: +919591152200, e-mail: suganthi.rangan@gmail.com

\section{INTRODUCTION}

Dental burs are more prone to contamination with necrotic tissue, saliva, blood, and potential pathogens during tooth preparation. Therefore, the sterilization of dental burs before and after clinical use is essential to prevent cross-infection. ${ }^{1}$ The use of effective infection control procedures in the dental office will prevent crosscontamination that may extend to dentist, dental staff, dental technician, and patients. ${ }^{2,3}$

Precleaning and sterilization of dental burs become difficult because of their small size and complex architecture. ${ }^{1}$ In the literature, the various techniques on sterilization of dental burs like glass bead, hot air oven, autoclave have been mentioned. ${ }^{2}$ However, cold sterilization has been routinely used due to our convenience and ease of use. ${ }^{4}$ Therefore, the purpose of the study is to compare the various cold sterilization techniques for sterilizing dental burs and diamond points by assessing the microbial growth in culture media on them before and after sterilization and also to evaluate and compare the amount of microbial growth between dental carbide burs and diamond points.

\section{AIM}

The aim of this study was to compare the efficacy of cold sterilization techniques of routinely used dental burs using four different disinfectants and also to compare the microbiological contamination of two types of burs:

1. Carbide burs

2. Diamond burs

\section{MATERIALS AND METHODS}

The following four disinfectants were used:

1. $2 \%$ glutaraldehyde

2. $5.2 \%$ sodium hypochlorite

3. Hydrogen peroxide

4. $70 \%$ ethanol

There were two main groups:

1. Group I-carbide burs

2. Group II-diamond burs

A total of 48 samples were collected, 12 samples per disinfectant. Each sample has two burs collected from same patient. One acts as control group, which means only microbial count was determined without disinfection. The other one would be determined with microbial count before and after disinfection. 


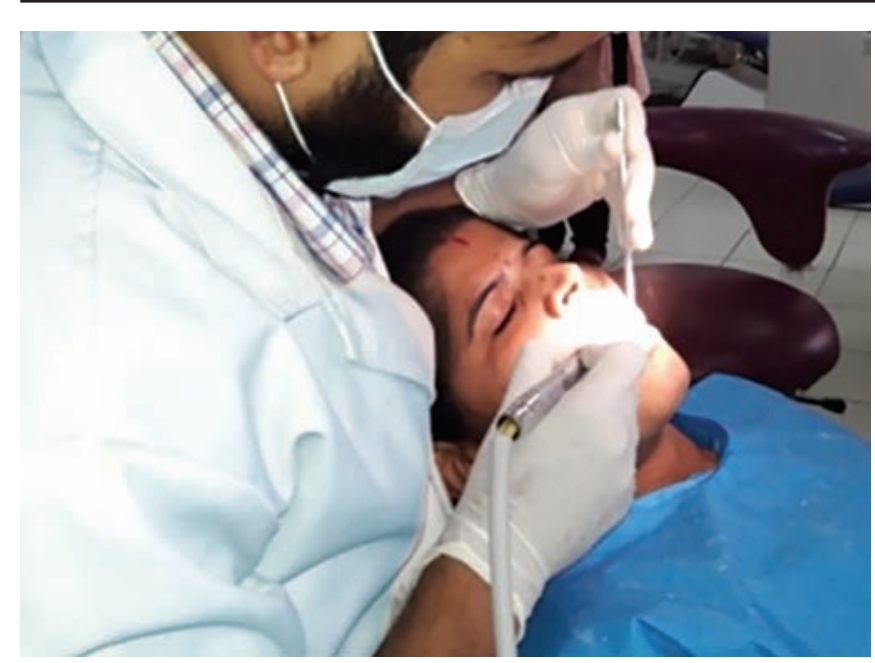

Fig. 1: Tooth preparation

After tooth preparation in patient, samples were collected in patients for tooth preparation using sterile forceps (Figs 1 and 2).

Each sample has two burs of which one is control group which is immersed directly in the BHI broth of about $2 \mathrm{~mL}$ in $5 \mathrm{~mL}$ test tube. Another bur was immersed directly in BHI broth. After stirring for 2 minutes, sample was removed with sterile tweezers and then immersed in $2 \mathrm{~mL}$ of disinfectants (Figs 3 and 4).

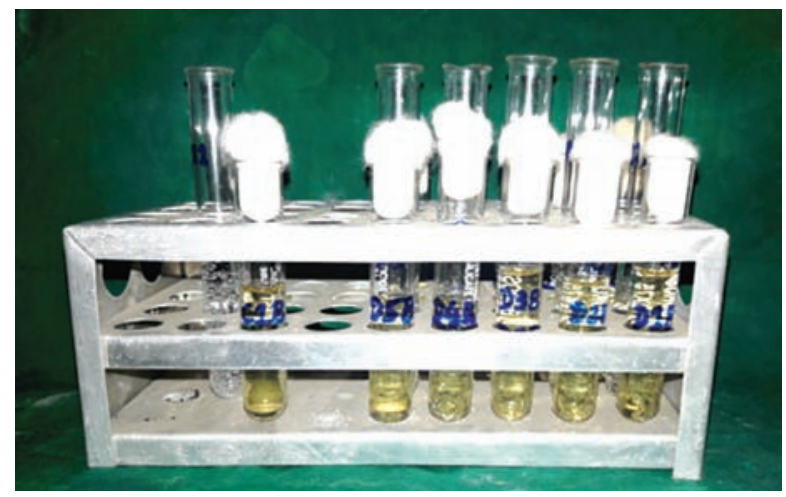

Fig. 3: BHI broth

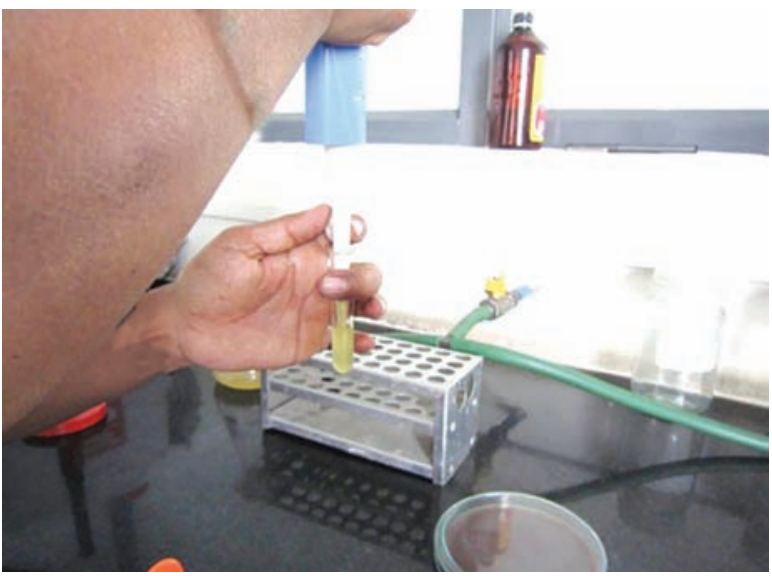

Fig. 5: A total of $100 \mu$ samples taken using micropipette

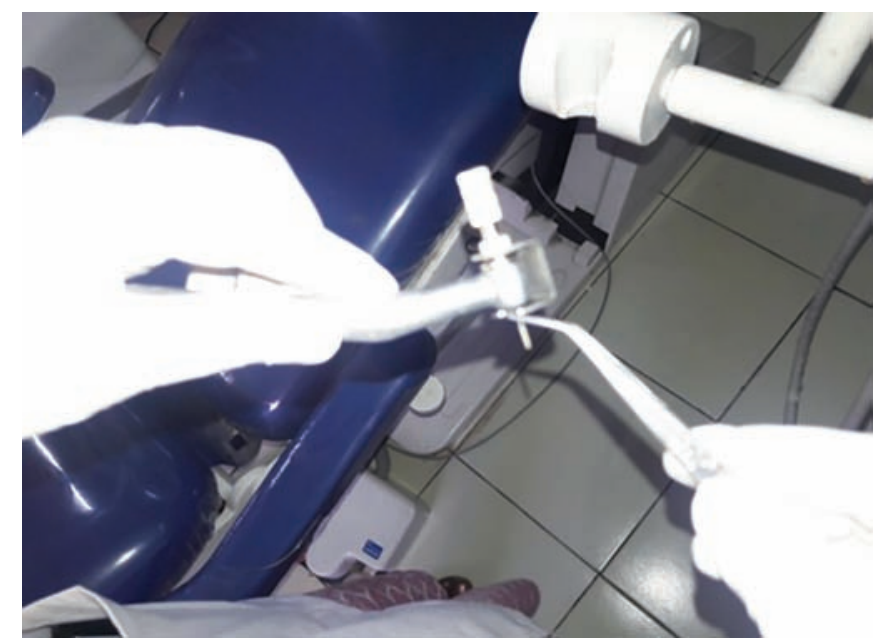

Fig. 2: Collection of samples using sterile tweezers

After contact time about 10 minutes of disinfection, the sample was removed from test tube and again immersed in the BHI broth. After stirring well for 2 minutes, remove the sample with sterile tweezers. This procedure was immediately followed by microbiological examination. Thus, the bacterial count was evaluated for both before and after disinfection.

About $100 \mu \mathrm{L}$ of sample from broth was plated onto $5 \%(\mathrm{v} / \mathrm{v})$ chocolate blood agar and MacConkey agar incubated at $37^{\circ} \mathrm{C}$ in $5 \%(\mathrm{v} / \mathrm{v}) \mathrm{CO}_{2}$ for 48 hours (Figs 5 to 7 ).



Fig. 4: Disinfectants

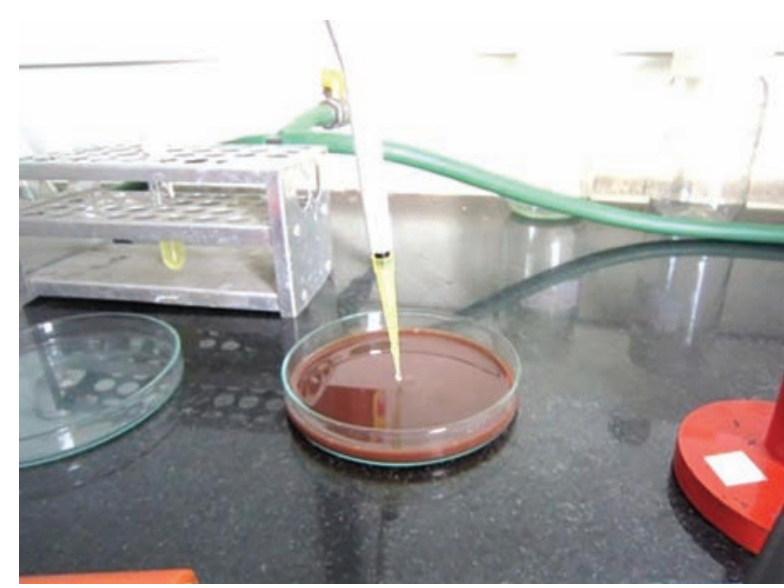

Fig. 6: Dispersing on the chocolate blood agar plate 


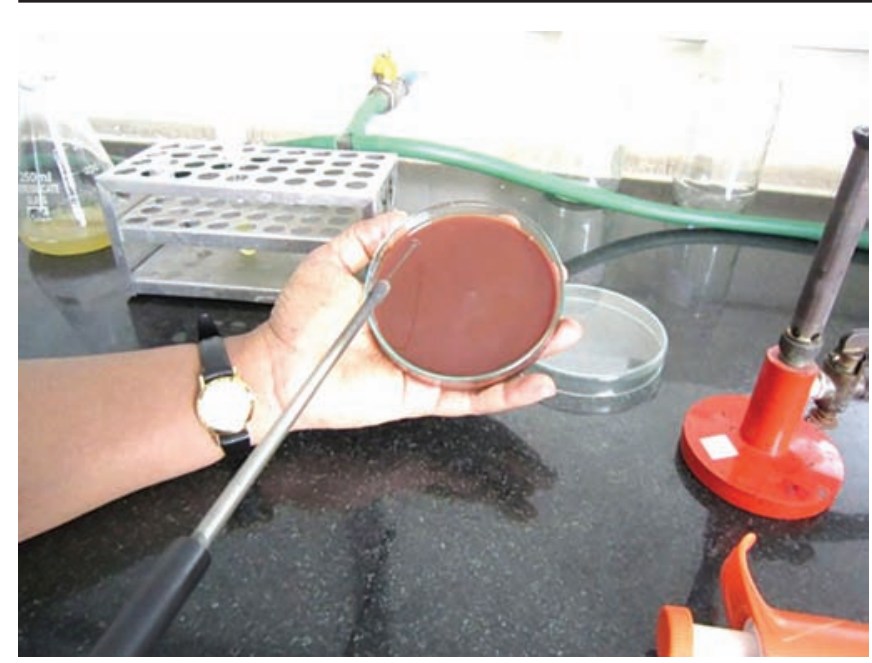

Fig. 7: Plating the chocolate blood agar

The bacterial count was obtained as colony-forming units (CFU) per mL. Presumptive identification of the colonies was done using chocolate blood agar and MacConkey agar.

\section{RESULTS}

The results are tabulated in Tables 1 to 8 based on before and after disinfection.

Table 1: Hydrogen peroxide group: group I carbide burs

\begin{tabular}{lll}
\hline$(n=4)$ & Before $(\mathrm{CFU} / \mathrm{mL})$ & After $(\mathrm{CFU} / \mathrm{mL})$ \\
\hline Culture +ve $=4$ & GPB $=80$ & GPB $=20$ \\
& GPC $=10$ & \\
Total & 90 & 20 \\
\hline
\end{tabular}

GPB: Gram-positive bacilli; GPC: Gram-positive cocci;

GNB: Gram-negative bacilli

Table 2: Hydrogen peroxide group: group II diamond points

\begin{tabular}{lll}
\hline$(n=8)$ & Before $(\mathrm{CFU} / \mathrm{mL})$ & After $(\mathrm{CFU} / \mathrm{mL})$ \\
\hline Culture +ve $=5$ & GPB $=350$ & GPB $=35$ \\
& GPC $=300$ & GPC $=40$ \\
& GNB $=20$ & GNB $=5$ \\
Total & 670 & 80 \\
\hline
\end{tabular}

GPB: Gram-positive bacilli; GPC: Gram-positive cocci; GNB: Gram-negative bacilli

Table 3: Glutaraldehyde group: group I carbide burs

\begin{tabular}{lll}
\hline$(n=4)$ & Before $(\mathrm{CFU} / \mathrm{mL})$ & After $(\mathrm{CFU} / \mathrm{mL})$ \\
\hline Culture +ve $=3$ & GPB $=60$ & GPB $=5$ \\
& GPC $=20$ & \\
Total & 80 & 5 \\
\hline
\end{tabular}

GPB: Gram-positive bacilli; GPC: Gram-positive cocci

Table 4: Glutaraldehyde group: group II diamond points

\begin{tabular}{lll}
\hline$(n=8)$ & Before $(\mathrm{CFU} / \mathrm{mL})$ & After $(\mathrm{CFU} / \mathrm{mL})$ \\
\hline Culture +ve $=6$ & GPB $=400$ & GPB $=15$ \\
& GPC $=350$ & \\
& GNB $=50$ & GNB $=5$ \\
Total & 800 & 20 \\
\hline
\end{tabular}

GPB: Gram-positive bacilli; GPC: Gram-positive cocci; GNB: Gram-negative bacilli
Table 5: Sodium hypochlorite: group I carbide burs

\begin{tabular}{lll}
\hline$(n=4)$ & Before $(\mathrm{CFU} / \mathrm{mL})$ & After \\
\hline Culture +ve $=4$ & GPB $=70$ & No growth \\
& GPC $=20$ & \\
Total & 90 & No growth \\
\hline
\end{tabular}

GPB: Gram-positive bacilli; GPC: Gram-positive cocci

Table 6: Sodium hypochlorite: group II diamond points

\begin{tabular}{lll}
\hline$(n=8)$ & Before $(\mathrm{CFU} / \mathrm{mL})$ & After \\
\hline Culture $+\mathrm{ve}=8$ & GPB $=400$ & No growth \\
& GPC $=350$ & \\
& GNB $=150$ & No growth \\
\hline
\end{tabular}

GPB: Gram-positive bacilli; GPC: Gram-positive cocci; GNB: Gram-negative bacilli

Table 7: Surgical spirit group: group I carbide burs

\begin{tabular}{lll}
\hline$(n=4)$ & Before $(\mathrm{CFU} / \mathrm{mL})$ & After $(\mathrm{CFU} / \mathrm{mL})$ \\
\hline Culture +ve $=4$ & GPB $=40$ & GPB $=5$ \\
& GPC $=45$ & \\
& GNB $=5$ & GNB $=5$ \\
Total & 90 & 10 \\
\hline
\end{tabular}

GPB: Gram-positive bacilli; GPC: Gram-positive cocci; GNB: Gram-negative bacilli

Table 8: Surgical spirit group: group II diamond points

\begin{tabular}{lll}
\hline$(n=8)$ & Before $(C F U / m L)$ & After $(C F U / m L)$ \\
\hline Culture +ve $=7$ & GPB $=450$ & GPB $=30$ \\
& GPC $=250$ & GPC $=30$ \\
& GNB $=50$ & GNB $=5$ \\
Total & 750 & 65
\end{tabular}

GPB: Gram-positive bacilli; GPC: Gram-positive cocci;

GNB: Gram-negative bacilli

Graphs 1 to 4 are the chart representations relating level of disinfection and bacterial count

The results were statistically analyzed by one-way ANOVA test and post hoc test (Tables 9 and 10).

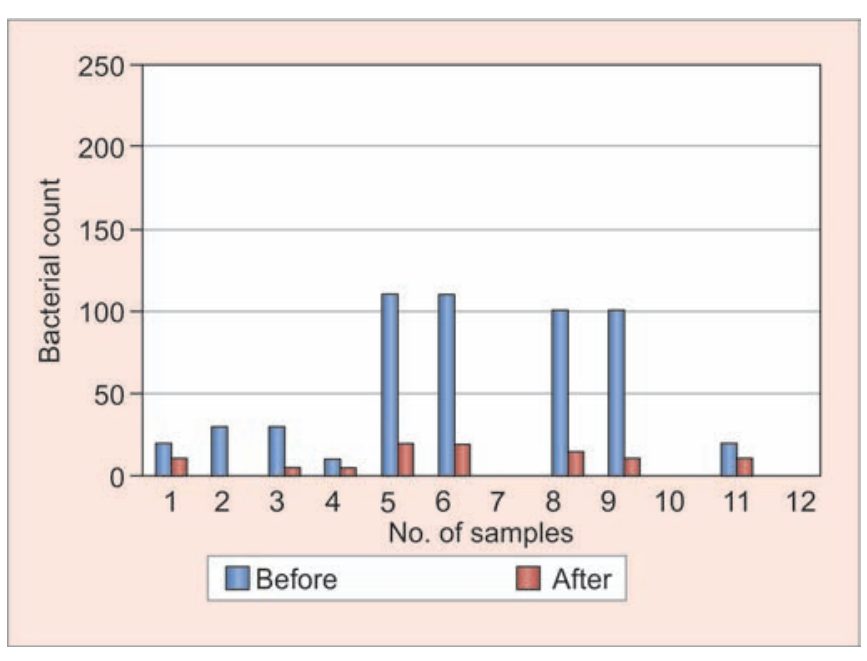

Graph 1: Hydrogen peroxide group 


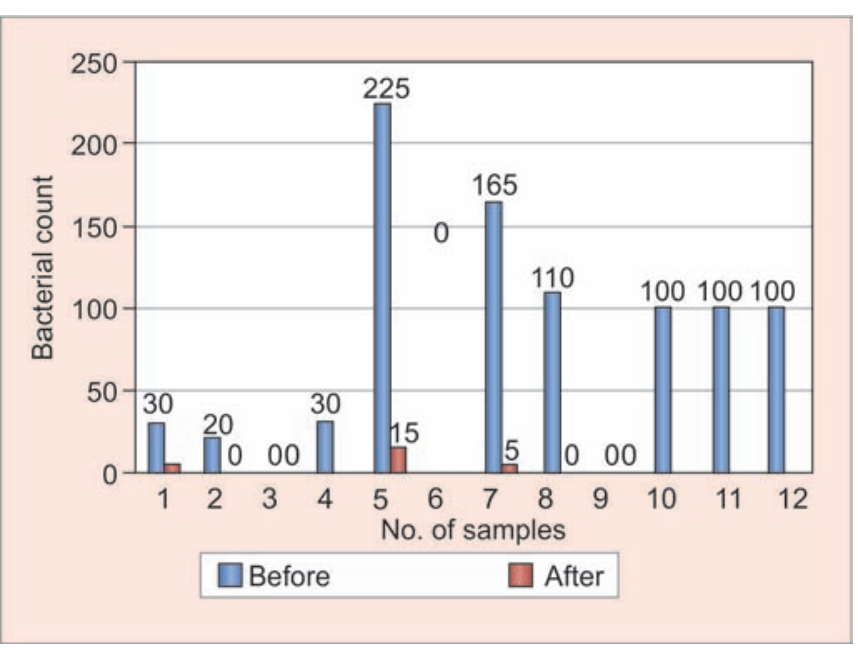

Graph 2: Glutaraldehyde group

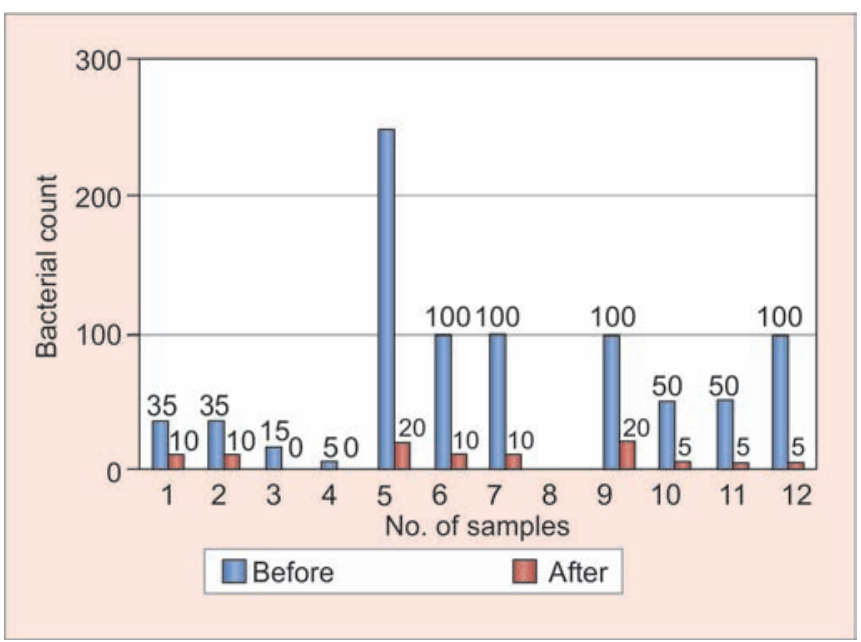

Graph 4: Surgical spirit group

Table 9: One-way ANOVA test

\begin{tabular}{lll}
\hline & F factor & Significant values \\
\hline Before & 0.245 & 0.864 \\
After & 6.533 & 0.001 \\
\hline
\end{tabular}

$p<0.05$, statistically significant

Table 10: Post hoc test: Dependent variable-after

\begin{tabular}{|c|c|c|c|c|}
\hline (I) group & (J) group & $\begin{array}{l}\text { Mean } \\
\text { difference }(I-J)\end{array}$ & $\begin{array}{l}\text { Standard } \\
\text { error }\end{array}$ & Significant \\
\hline \multirow[t]{3}{*}{1} & 2 & 6.250 & 2.596 & 0.143 \\
\hline & 3 & $8.333^{*}$ & 2.247 & 0.019 \\
\hline & 4 & 0.417 & 3.002 & 1.000 \\
\hline \multirow[t]{3}{*}{2} & 1 & -6.250 & 2.596 & 0.143 \\
\hline & 3 & 2.083 & 1.300 & 0.534 \\
\hline & 4 & -5.833 & 2.377 & 0.128 \\
\hline \multirow[t]{3}{*}{3} & 1 & $-8.333^{*}$ & 2.247 & 0.019 \\
\hline & 2 & -2.083 & 1.300 & 0.534 \\
\hline & 4 & $-7.917^{*}$ & 1.990 & 0.012 \\
\hline \multirow[t]{3}{*}{4} & 1 & -0.417 & 3.002 & 1.000 \\
\hline & 2 & 5.833 & 2.377 & 0.128 \\
\hline & 3 & $7.917^{\star}$ & 1.990 & 0.012 \\
\hline
\end{tabular}

*The mean difference is significant at the 0.05 level

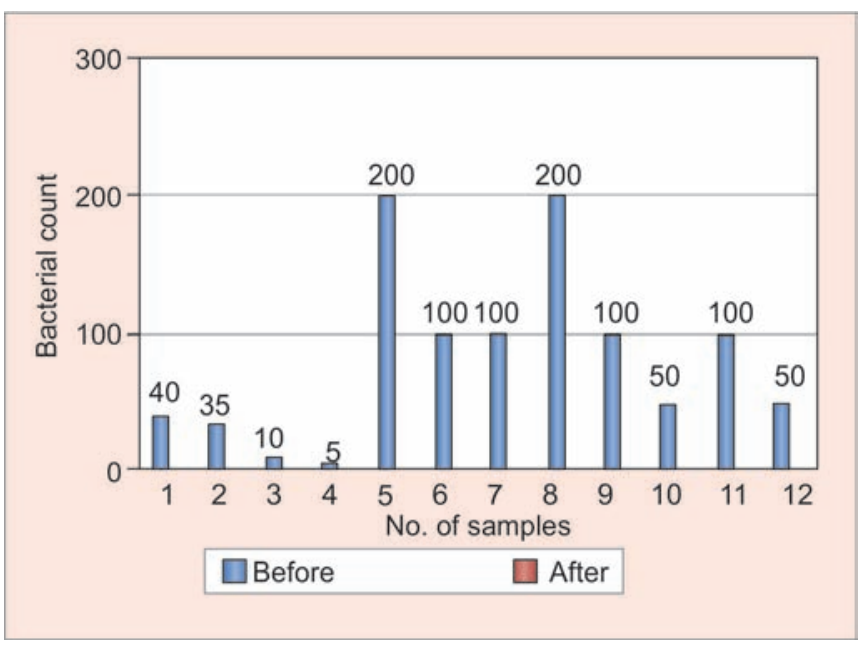

Graph 3: Sodium hypochlorite group

The results revealed that all four disinfectants showed clinical significance in disinfection. There was statistically significant difference between sodium hypochlorite and hydrogen peroxide, sodium hypochlorite and surgical spirit. However, there was no statistically significant difference between sodium hypochlorite and glutaraldehyde. Sodium hypochlorite and glutaraldehyde are the most effective disinfectants than hydrogen peroxide followed by surgical spirit, which is the least effective disinfectant.

\section{DISCUSSION}

Dental burs are heavily contaminated with necrotic tissue, saliva, blood, and potential pathogens during use. ${ }^{5}$ Burs have complex architecture that makes precleaning and subsequent sterilization difficult to achieve. ${ }^{6}$ Risk of crossinfection between patients due to inadequate sterilization leads to the development of certain diseases like hepatitis B, etc. ${ }^{7}$ The British Dental Association recommends that any reusable dental instrument which comes into contact with oral fluids must be properly cleaned and sterilized before use. ${ }^{8}$ Resterilization ${ }^{9}$ is defined as "repeated application of a terminal process designed to remove or destroy all viable forms of microbial life, including bacterial spores, to an acceptable sterility assurance level."

Whitworth et $\mathrm{al}^{1}$ conducted a study that compared the efficacy of various methods of precleaning and sterilizing of dental burs by manual cleaning, enzymic agents, and washer-disinfectors. This study recommended the use of washer-disinfectors for presterilization cleaning of contaminated dental burs. ${ }^{10}$ Morrison and Conrod ${ }^{11}$ compared the effectiveness of various sterilization techniques currently used in dentistry for the resterilization of dental burs and endodontic files. In this study the sterility of new (unused) and used dental burs and endodontic files before and after various sterilization procedures was analyzed. They finally concluded that dental burs 
and endodontic files, as packaged by the manufacturer, are not sterile and should therefore be sterilized before first use. Fais et $\mathrm{l}^{12}$ compared the cutting capacity of carbide burs sterilized with microwaves and traditional sterilization methods: Dry heat (G1), autoclave (G2), microwave irradiation (G3), glutaraldehyde (G4) or control-no sterilization (G5). Sterilization by dry heat was the one that least affected the cutting capacity of the carbide burs and microwave sterilization was not better than traditional sterilization methods. Microwave sterilization is one of the recent advances which has low cost, speed, and simplicity of disinfection. Sajjanshetty et $\mathrm{al}^{13}$ have conducted a study where 96 round diamond burs were selected and divided into six groups. These burs were used for the access cavity preparation to get contamination and subjected for bacteriological culture. After getting baseline data, burs were subjected to manual scrubbing, hot air oven, glass bead sterilizer, ultrasonic cleaner, and autoclave to get postdecontamination data, which revealed that none of the methods used were found to be absolutely efficacious in the decontamination of dental burs. However, among the experimental groups used in the present study, autoclave was found to be the relatively best method.

In all previous literature, the methods like manual scrubbing to autoclave sterilization were explained; autoclave was the best method to sterilize the dental burs. But this method is expensive, time consuming, and cannot be implemented in shorter time especially in between patient appointments. Cold sterilization may be a good alternative in case of short time for disinfecting dental burs. However, none of the literature compared the effectiveness of cold sterilization techniques using various disinfectants. This study revealed the efficacy of sodium hypochlorite and glutaraldehyde for disinfection of dental burs of daily use. In this study, the contact time and quantity of disinfection was standardized as 10 minutes and $2 \mathrm{~mL}$ for all disinfectants. Sodium hypochlorite is a strong, fast-acting oxidizing, ${ }^{14}$ bactericidal, and proteolytic agent. ${ }^{15}$ It is also a hydrolyzing agent. ${ }^{16}$ It is an effective sporicidal than glutaraldehyde. ${ }^{17}$ The antimicrobial effectiveness of sodium hypochlorite, based in its high pH (hydroxyl ion action), interferes in the cytoplasmic membrane integrity with an irreversible enzymatic inhibition. ${ }^{14}$ It has tendency to corrode most metals except titanium and some forms of stainless steel but when used in an ideal concentration and duration of exposure sodium hypochlorite serves as a disinfectant on the contaminated dental instruments. ${ }^{18,19}$ According to biosafety measures, contact time will be 10 minutes and chlorine solutions should not be mixed or stored with cleaning products containing ammonia, ammonium chloride, or phosphoric acid. Combining these chemicals will result in the release of a chlorine gas, which can cause nausea, eye irritation, tearing, headache, and shortness of breath. ${ }^{20}$ Due to its oxidizing nature, it is corrosive to metals; however, autoclave can cause high corrosion to metals when compared with sodium hypochlorite. ${ }^{21}$ The minimum inhibitory concentration (lowest concentration of disinfectant agent required to reduce bacterial count) is 150 to $4,491 \mathrm{mg} / \mathrm{L}$ of chlorine-releasing agents when compared with 1,375 to $3,250 \mathrm{mg} / \mathrm{L}$ of glutaraldehyde. ${ }^{22}$ Glutaraldehyde was classified as a high level of disinfection. ${ }^{20}$ It is the most commonly used disinfectant in the dentistry. In vivo study showed that antimicrobial activity of Asporin ( $2 \%$ alkaline glutaraldehyde) required $1 \mathrm{~min}$ killing time for almost all instruments. ${ }^{23}$ Burs and files sterilized by immersing in glutaraldehyde (2.4\%) for 12 hours revealed complete sterilization. ${ }^{24}$ However, the chlorine-containing compound was the effective disinfectant against hepatitis B virus than glutaraldehyde, which requires ultrasonication. ${ }^{25}$ It is noncorrosive when compared with sodium hypochlorite, so it is safer to use for dental burs; however, glutaraldehyde solutions should be discarded if they become turbid. It is toxic and an irritant to skin and mucous membranes, and contact with it must be avoided. ${ }^{20}$

In this study, there was no statistical difference found between sodium hypochlorite and glutaraldehyde. As this study involved less sample size, more sample size and further research are required to compare the level of disinfection between sodium hypochlorite and glutaraldehyde. Coming to hydrogen peroxide, it is a strong oxidizing agent like chlorine, but it is safer than chlorine to the humans and environment. It can be used as a disinfectant for disinfecting heat-sensitive medical/dental devices. ${ }^{20}$ It requires ultrasonication to destroy hepatitis B virus when compared with chlorinecontaining compounds. ${ }^{25}$ It is corrosive to metals like brass, zinc and copper except stainless steel. So, it is safer to use in stainless steel dental burs. The study done by Finnegan et $\mathrm{al}^{26}$ revealed that gaseous hydrogen peroxide is a more effective oxidizing agent than liquid hydrogen peroxide. In this study, the hydrogen peroxide showed clinical significance in disinfection of dental burs but there was significant difference between sodium hypochlorite and hydrogen peroxide. Surgical spirit (70\% alcohol) shows intermediate level of disinfection. ${ }^{20}$ They are active against vegetative bacteria, fungi, and lipid-containing viruses but not against spores unlike sodium hypochlorite. In this study, though it was less effective than sodium hypochlorite the disinfection level of surgical spirit was clinically significant. So surgical spirit can be used for disinfecting dental burs of daily routine practice. 


\section{CONCLUSION}

According to the Centers for Disease Control and Prevention guidelines, to prevent cross-contamination, decontamination of dental burs is necessary in daily routine practice. There are various factors that determine choice of disinfection like toxicity to the patient and/or dentist, any damage to the instrument, cost, stability, the degree of microbial killing required, and ability of disinfectant to kill microorganisms rapidly. Autoclave is the best method of sterilization of dental burs but due to cost and time-consuming nature, cold sterilization acts as a good alternative in disinfection of dental burs. The results of this study revealed that sodium hypochlorite and glutaraldehyde are most effective than hydrogen peroxide and surgical spirit is the least effective disinfectant. However, there was clinical significance in the level of disinfection of all four disinfectants.

\section{REFERENCES}

1. Whitworth CL, Martin MV, Gallagher M, Worthington HV. A comparison of decontamination methods used for dental burs. Br Dent J 2004 Nov;197(10):635-640.

2. Crawford JJ, Whitacre RJ, Middaugh DG. Current status of sterilization instruments, devices and method for the dental office. J Am Dent Assoc 1981 May;102(5):683-689.

3. Engelhardt JP, Grun L, Dahl HJ. Factors affecting sterilization in glass bead sterilizers. J Endod 1984 Oct;(10):465-470.

4. Spyros E. Halikis, The use of chemical disinfectants in the dental surgery, Australian Dental Journal, December, I962, 445-450.

5. Gureckis KM, Burgess JO, Schwartz RS. Cutting effectiveness of diamond instruments subjected to cyclic sterilization methods. J Prosthet Dent 1991 Dec;66(6):721-726.

6. Harkness N, Davies EH. The cleaning of dental diamond burs. Br Dent J 1983 Jan;154(2):42-45.

7. Leontiou AP, Coogan MM, Aspinall S. Disinfection of dental diamond burs contaminated with hepatitis B virus. J Prosthet Dent 1999 Sep;82(3):332-335.

8. American Dental Association. Sterilization and disinfection of dental instruments. Chicago (IL): ADA; 2009. [cited 2015 Jan 22]. Available from: http://www.ada.org/ / media/ADA/ Member\%20Center/FIles/cdc_sterilization.ashx.

9. Dunn D. Reprocessing single-use devices - the ethical dilemma. AORN J 2002 May;75(5):989-999.

10. Angelillo F, Bianco A, Nobile CGA, Pavia M. Evaluation of the efficacy of glutaraldehyde and peroxygen for disinfection of dental instruments. Lett Appl Microbiol 1998 Nov;27(5): 292-296.
11. Morrison A, Conrod S. Dental burs and endodontic files: are routine sterilization procedures effective? JCDA 2009 Feb;75(1):39-43.

12. Fais LM, Pinelli LA, Adabo GL, Silva RH, Marcelo CC, Guaglianoni DG. Influence of microwave sterilization on the cutting capacity of carbide burs. J Appl Oral Sci 2009 NovDec;17(6):584-589.

13. Sajjanshetty S, Hugar D, Hugar S, Ranjan S, Kadani M. Decontamination methods used for dental burs-a comparative study. J Clin Diagn Res 2014 Jun;8(6):ZC39-ZC41.

14. Belinda TJ, Muralidharan NP. An efficacy of sodium hypochlorite in disinfecting the contaminated dental instruments. J Pharm Sci Res 2015 Aug;7(8):563-565.

15. Dakin HD. On the use of certain antiseptic substances in the treatment of infected wounds. Br Med J 1915 Aug;2(2852): 318-320.

16. Pashley EL, Birdsong NL, Bowman K, Pashley DH. Cytotoxic effects of $\mathrm{NaoCl}$ on vital tissues. J Endod 1985 Dec;11(12): 525-528.

17. Sagripanti JL, Bonifacino A. Comparative sporicidal effects of liquid chemical agents. Appl Environ Microbiol 1996 Feb;62(2):545-551.

18. Mark, HF.; McKetta, JJ.; Othmer, DF. Encyclopedia of chemical technology. 2nd ed. New York: Interscience; 1964. p. 10-15.

19. Selinger, B. Chemistry in the marketplace. 4 th ed. Sydney: Harcourt Brace Jovanich; 1989. p. 55-56.

20. U.S. Department of Health and Human Services Centers for Disease and Preventions. 5th Edition. National Institutes of Health; 2009. HHS Publication No. (CDC) 21-112: Biosafety in Microbiological and Biomedical Laboratories (BMBL)

21. Yang W-K, Ra Y-S, Lee Y-K, Son H-H, Kim M-R. The effect of $\mathrm{NaOCl}$ treatment and sterilization procedures on the corrosion of endodontic files. J Kor Acad Cons Dent 2005 Mar;30(2): 121-127.

22. Penna TC, Mazzola PG, Martins AM. The efficacy of chemical agents in cleaning and disinfection programs. BMC Infect Dis 2001 Sep;1:16.

23. Angelillo IF, Bianco A, Nobile CG, Pavia M. Evaluation of the efficacy of glutaraldehyde and peroxygen for disinfection of dental instruments. Lett Appl Microbiol 1998 Nov;27(5): 292-296.

24. Kumar KV, Kiran Kumar KS, Supreetha S, Raghu KN, Veerabhadrappa AC, Deepthi S. Pathological evaluation for sterilization of routinely used prosthodontic and endodontic instruments. J Int Soc Prev Community Dent 2015 MayJun;5(3):232-236.

25. Leontiou AP, Coogan MM, Aspinall S. Disinfection of dental diamond burs contaminated with hepatitis B virus. J Prosthet Dent 1999 Sep;82(3):332-335.

26. Finnegan M, Linley E, Denyer SP, McDonnell G, Simons C, Maillard JY. Mode of action of hydrogen peroxide and other oxidizing agents: differences between liquid and gas forms. J Antimicrob Chemother 2010 Oct;65(10):2108-2115. 